\title{
$\mathcal{I}_{\text {nvestigación IMA }}^{\text {REVTA }}$
}

\section{PERSPECTIVAS DE LA INVESTIGACIÓN EN EL INSTITUTO MILITAR AERONÁUTICO}

\section{Olga Beatriz Orozco Asesora Metodológica IMA}

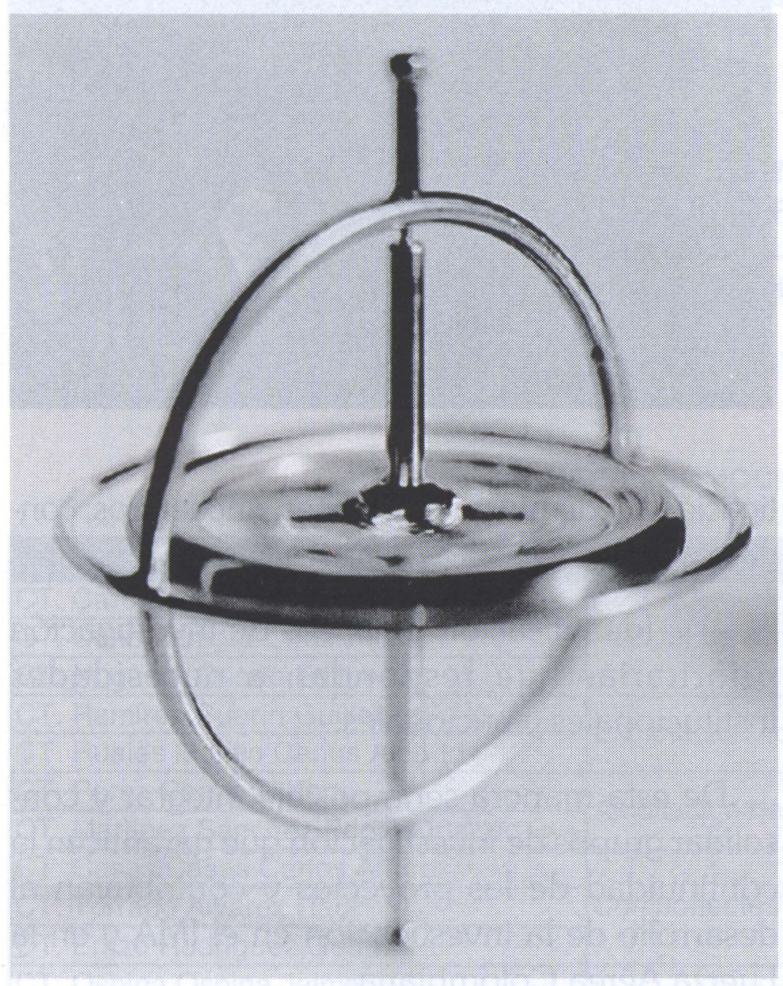

Dicen los expertos que sin investigación no hay desarrollo posible; la ciencia y la tecnología tienen en la actualidad una importancia estratégica en el avance de una institución, de una región o de un país. Por lo tanto, para lograr el desarrollo social, económico, cultural y político, se requiere una alta productividad científica lo cual significa, según COLCIENCIAS, contar con:

Calidad: Es la excelencia demostrada mediante el reconocimiento de los pares (expertos) y de la sociedad en general, de los resultados de la investigación. Para ello es indispensable un alto nivel de formación de los investigadores, autonomía organizacional y financiera, capacidad de gestión, planes de desarrollo a corto, mediano y largo plazo e interacción con otros grupos y centros de investigación.

Pertinencia: Es la capacidad para contribuir mediante la investigación, a la solución de problemas más relevantes de un grupo, de una co- munidad o de la sociedad en general, es decir, que responda a sus necesidades e intereses.

Visibilidad: Es el impacto en la sociedad de un plan, programa o proyecto de investigación, por su parte a un campo específico del conocimiento. Se evidencia mediante las publicaciones, la participación en eventos científicos y en general, a través de la socialización de los resultados de la investigación.

Estabilidad: Es la capacidad para diseñar y desarrollar planes y programas de investigación de mediano y largo plazo; esto significa autonomía financiera y organizacional.

Si estas condiciones se cumplen, es posible que la investigación se convierta en factor estratégico del desarrollo institucional. Las políticas de modernización de las Fuerzas Militares, exigen un gran esfuerzo en este sentido, teniendo en cuenta la actual situación de conflicto por la

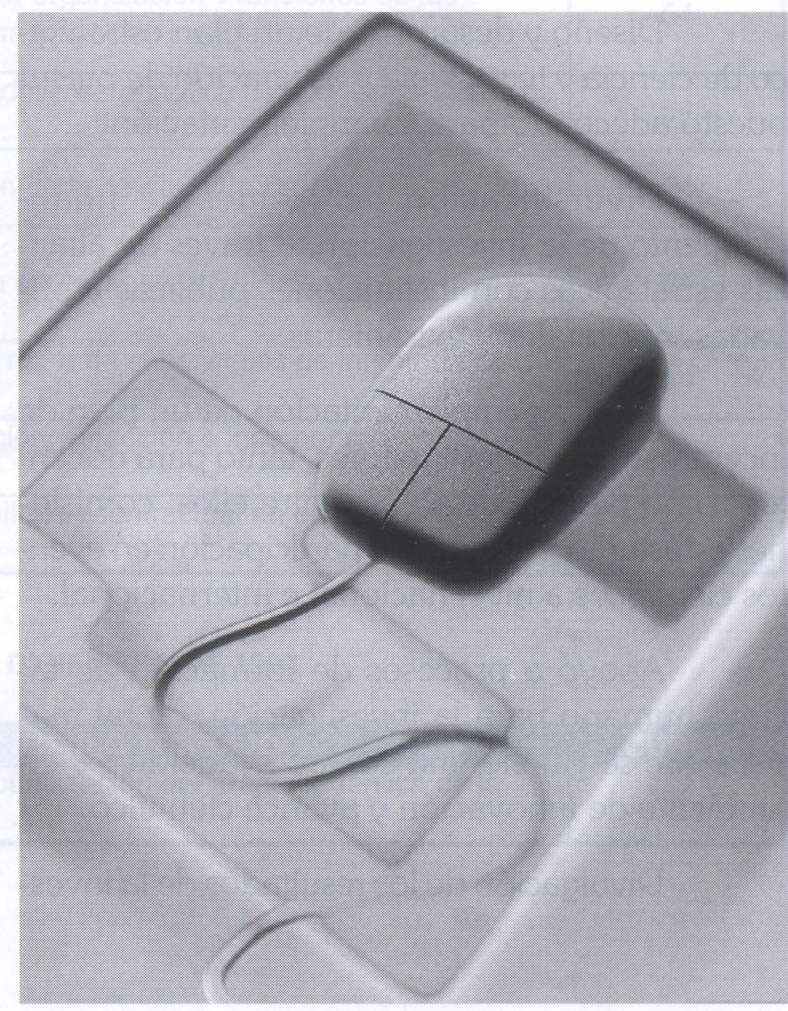


que atraviesa el país y el acelerado avance de las nuevas tecnologías. Para ello es necesario enfatizar en la formación científico-técnica del militar, para que esté en capacidad de apropiarse de un entorno en permanente cambio.

En este contexto, a la Fuerza Aérea le corresponde promover el avance científico y tecnológico en su campo de acción y el Instituto Militar Aeronáutico (IMA) como responsable de la especializacion de sus hombres y mujeres, es el espacio académico propicio para desarrollar la investigación, orientada a generar e implementar innovaciones que contribuyan al cumplimiento de su misión.

La actividad científica también debe estar dirigida al mejoramiento de la calidad de los procesos de formación y especialización de los integrantes de la Fuerza Aérea; las innovaciones pedagógicas son hoy una obligación para las instituciones que no quieren quedarse rezagadas del avance vertiginoso en todos los campos del conocimiento.

Con esta perspectiva, se deben implementar estrategias para desarrollar y consolidar la investigación en el IMA, entre ellas:

- Diseño y desarrollo de un plan estratégico de ciencia y tecnología y asignación de presupuesto adecuado para su implementación.

- Diversificación de fuentes de financiamiento de la investigación, a través de alianzas estratégicas con instituciones públicas y privadas, nacionales y extranjeras.

Diseño e implementación de un plan de incentivos a los investigadores, tanto para docentes como para estudiantes, entre ellos: comisiones de estudio, concursos y participación en eventos científicos a nivel nacional e internacional.

- Apoyo a procesos de formación de talento humano para la investigación, de tal manera que se genere una cultura académica y un ambiente de innovación y avance científico.

- Divulgación de los resultados de la inves-

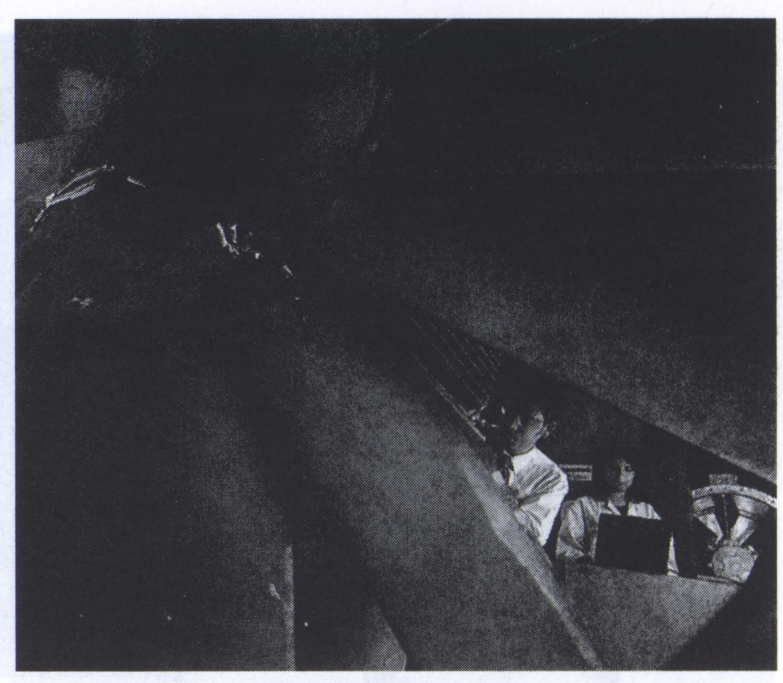

tigación mediante publicaciones, encuentros, congresos y otros eventos académicos.

- Identificación de líneas de investigación prioritarias que respondan a necesidades institucionales y nacionales.

De esta manera sería posible integrar y consolidar grupos de investigación que garanticen la continuidad de los proyectos y contribuyan al desarrollo de la investigación en el IMA y en la Fuerza Aérea Colombiana.

El futuro de la institución y del país, está entonces en manos de los investigadores; a ellos les debemos todo el apoyo y reconocimiento para que su talento sea la riqueza más valorada por todos los colombianos.

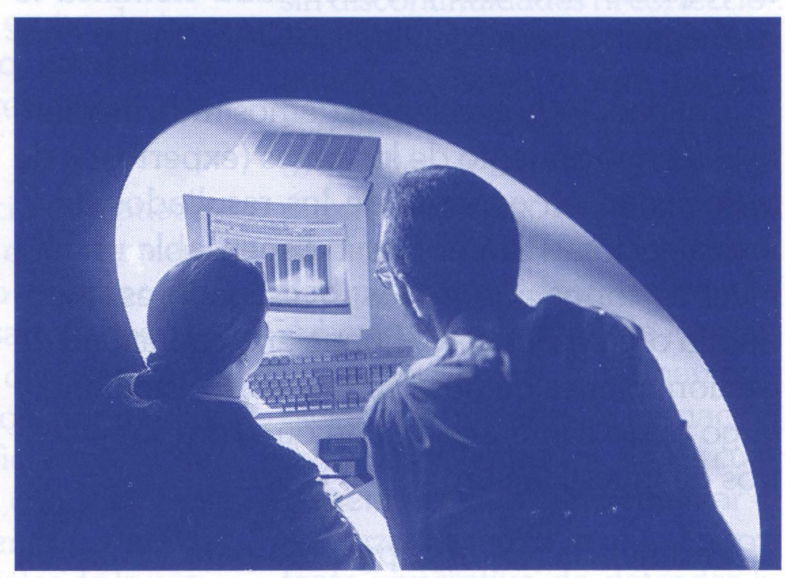

